\title{
Predicting Operational Energy Consumption Profiles - Findings from Detailed Surveys and Modelling in a UK Educational Building Compared to Measured Consumption
}

\section{Knight, S. Stravoravdis \& S. Lasvaux}

To cite this article: I. Knight, S. Stravoravdis \& S. Lasvaux (2008) Predicting Operational Energy Consumption Profiles - Findings from Detailed Surveys and Modelling in a UK Educational Building Compared to Measured Consumption, International Journal of Ventilation, 7:1, 49-57, DOI: 10.1080/14733315.2008.11683798

To link to this article: https://doi.org/10.1080/14733315.2008.11683798

曲 Published online: 29 Mar 2016.

Submit your article to this journal ๘

山 Article views: 29 


\title{
Predicting Operational Energy Consumption Profiles - Findings from Detailed Surveys and Modelling in a UK Educational Building Compared to Measured Consumption
}

\author{
I Knight $^{1}$, S Stravoravdis ${ }^{1}$ and S Lasvaux ${ }^{2}$ \\ ${ }^{1}$ Welsh School of Architecture, Cardiff University, UK \\ ${ }^{2}$ INSA de Toulouse, France
}

\begin{abstract}
This paper presents the preliminary findings from the first stage of a physical survey and modelling case study conducted to obtain modelled and actual energy consumption profiles for a UK multi-storey mixed use educational building (the Bute building at the University of Wales, Cardiff). The purpose of the study is to provide an insight into how accurately current models and software can predict the actual energy consumption in such a building, with a view to informing the development of operational and asset ratings for buildings in the EU as part of the Energy Performance in Buildings Directive (EPBD) Article 7 requirements. The models used in this study were the software tool ECOTECT and the SBEM (Simplified Building Energy Methodology) version of the UK's national calculation methodology. The study also briefly discusses the potential problems inherent in the use of modelling techniques for assessing the energy performance of buildings.
\end{abstract}

The data obtained through this study enabled predicted energy consumption profiles for both heating/cooling and electrical energy use to be obtained, as well as a UK SBEM asset-type compliance rating. The predicted profiles and compliance rating were then compared to the monitored actual energy consumption profiles obtained over the same period. It was seen that the various modelling approaches gave a reasonable prediction of the gas consumption and a reasonable estimate of the electrical consumption using the SBEM. However, overall it was felt that further case studies would need to be tested to have any confidence in these findings. The relative agreement between the SBEM results in this case study and the measured consumption supports the view that for prediction of electrical consumption then statistically derived numbers, such as benchmarks, are likely to enable reasonably confident predictions of energy use by generic activity type.

Key words: predicted energy use, measured energy use, SBEM, EPBD, ECOTECT, operational ratings, asset ratings, educational buildings.

\section{Introduction}

The aim of this work was to examine, via a case study of a real building (the Bute building at the University of Wales, Cardiff), some current building energy use prediction models and techniques to assess how accurately they predict the actual energy consumption occurring. The study will thus provide information which will help the development of building energy use prediction tools through identifying the types and forms of data needed to make these as accurate as possible in the context of real building uncertainties.

This study took place against a backdrop of the practical implementation of the EU Energy Performance of Buildings Directive (EPBD, 2003).
The primary aim of the EPBD is to assist Member States towards achieving buildings which consume less energy. As uncertainty over energy prices and availability also increase, then this call is being echoed by clients as well. These two powerful market drivers mean that the design and procurement of low energy buildings is becoming a mainstream requirement for building designers and operators. They are therefore looking for tools and advice to help them achieve this aim. However, despite decades of advances in tools in this area we are still in the relative infancy of being able to accurately predict the energy performance of real buildings occupied by real people undertaking real activities. The current state of the art is struggling to consistently predict the performance of simple buildings with simple occupancy. 
The lack of progress in this area has not stopped many countries introducing legislation which requires the prediction of the energy performance of buildings as part of their design requirements. They also provide tools, generally based on the CEN umbrella document PG-N37 (see EBPD 2002) to help show compliance. These tools normally use the heat balance method of assessing gains and losses within zones in a building. The potential problem with these tools is that they will be used to design new buildings, or alterations to existing buildings, to try and achieve the best rating they can. The questions therefore have to be 'how much can we rely on these tools?' when using them to assess the actual performance in use of a building, and 'does accuracy matter in this situation?' If the long-term purpose of the EPBD legislation is to assist in reducing energy consumption then perhaps accuracy is not so important, but if the aim is to eventually produce buildings which consume a known amount of energy in a 'resource poor' future then clearly the accuracy of this prediction is important.

This paper presents a research study to explore how accurately a building survey and two current building energy prediction tools were able to predict the actual consumption in a UK mixed use educational building, representing a building of reasonable complexity in size, shape and occupancy. The paper also presents the findings of an occupant questionnaire in the same building.

The two software tools used to assess the building's heating and cooling needs were the software tool ECOTECT (www) and the SBEM (Simplified Building Energy Methodology) (www) version of the UK's National Calculation Methodology.

The differences between the tools are not discussed here other than to note that the timesteps over which they calculate their results vary from 1 hour (ECOTECT) to monthly for SBEM (hence the "simplified" term), and that neither are claiming great accuracy in energy predictions. ECOTECT is intended as an early stage design tool, providing rapid calculation of the approximate energy performance of the space. SBEM is designed to use the CEN methodology along with pre-defined activity types to assess the likely energy consumption of a building for building regulation compliance purposes.

Enough building related information for both tools to be run could be gathered from a paper exercise and this is what is likely to happen in practice. In addition, this case study has also used a physical survey to obtain more precise details of the small power and equipment loads in the building, along with an occupant questionnaire to assess when this equipment was likely to have been used, and when the occupants were present. The information collected by the survey did not provide information on the usage profiles of equipment in those rooms which were for common use, or the more complex laboratory and media laboratories. One of the questions for the work was how much difference this might potentially make if we were to assume that these rooms could be described by the occupied room usage profiles.

The predictions of energy use gained from the tools and survey were compared against 'reality' in the form of the half hourly electricity data metered for the building over a year, and the monthly gas consumption data for a year.

\section{Brief Findings from the Physical Survey}

The physical survey of the case study building took place over a period of 4 weeks and examined over 300 separate spaces in the building. The survey specifically aimed to establish the location and average power consumption of energy consuming equipment in the building, along with obtaining information on the layout and fabric of the building suitable for modelling purposes. The building was predominantly naturally ventilated.

Some brief findings from the survey are:

- The average floor area per occupant was $16 \mathrm{~m}^{2}$;

- The average small power load in the building was $18.6 \mathrm{~W} / \mathrm{m}^{2}$;

- The average installed lighting load in the building was $16.2 \mathrm{~W} / \mathrm{m}^{2}$;

- The installed building services electrical load in the building was $1.2 \mathrm{~W} / \mathrm{m}^{2}$ excluding mechanical ventilation and air conditioning;

- The estimated average installed electrical load in the building was $35.9 \mathrm{~W} / \mathrm{m}^{2}$;

- The total installed capacity for gas was $1380 \mathrm{~kW}$ and that identified for electricity was $399 \mathrm{~kW}$

- The installed boiler capacity was $124 \mathrm{~W} / \mathrm{m}^{2}$. 
Average Bute Building kWh per half hour - May 2006 to April 2007 (multiply $x 2$ to get average Max Demand)

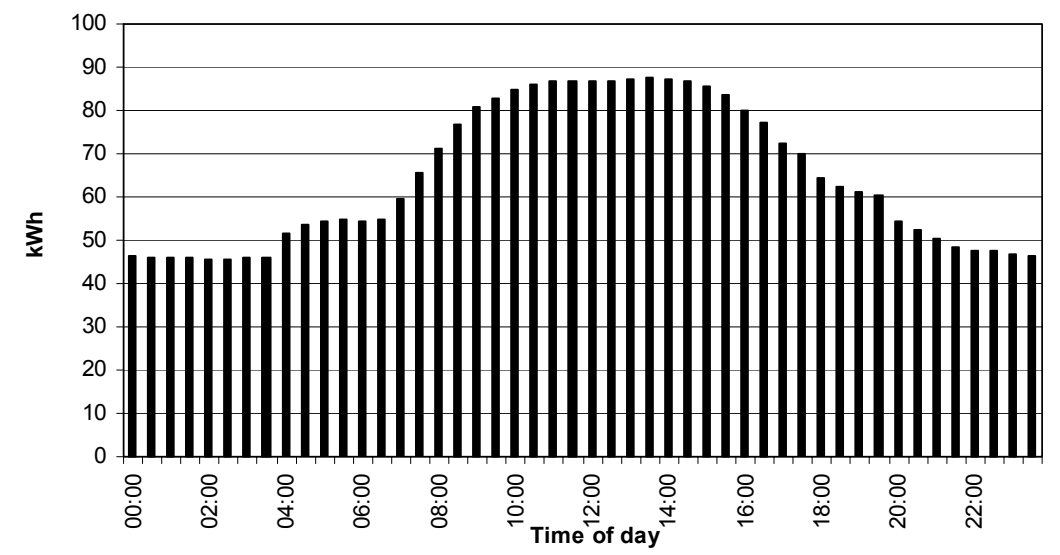

Figure 1. Average half-hourly electricity consumption for the whole year.

Bute Building Monthly Electricity Consumption - May 2006 to April 2007

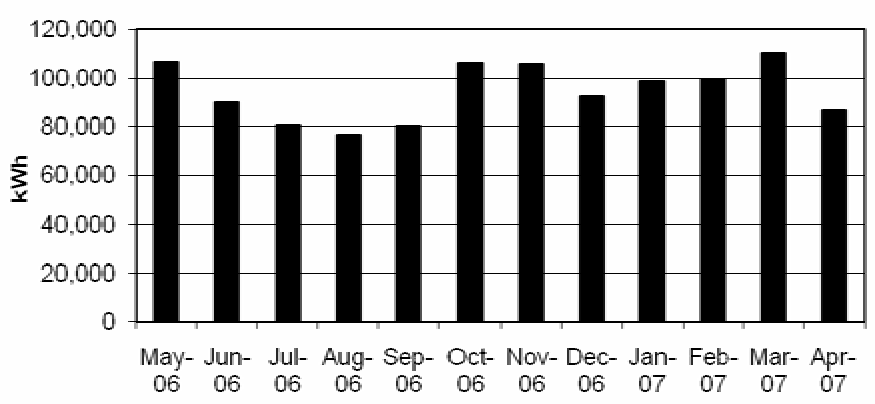

Figure 2. Monthly electricity consumption.

Bute Building Monthly Gas Consumption - May 2006 to April 2007

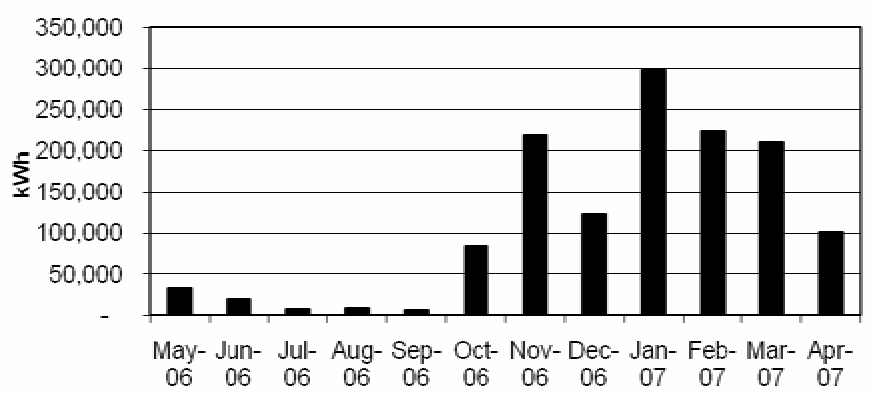

Figure 3. Monthly gas consumption. 


\subsection{Actual Consumptions}

The actual electrical and gas consumptions for the Bute building over the year ending April 2007 were $1133307 \mathrm{kWh}$ and $1331892 \mathrm{kWh}$ respectively. Normalised for floor area, these figures equate to $102 \mathrm{kWh} / \mathrm{m}^{2}$.a $\left(11.6 \mathrm{~W} / \mathrm{m}^{2}\right.$.a) for electricity, and $119 \mathrm{kWh} / \mathrm{m}^{2}$.a $\left(13.7 \mathrm{~W} / \mathrm{m}^{2}\right.$.a) for gas. Correcting the gas consumption for the effects of the weather using degree days gives a figure of $191 \mathrm{kWh} / \mathrm{m}^{2}$.a.

Figure 1 shows the metered average half hourly electricity consumption for the whole building over the year ending April 30th 2007. This figure shows that the average 'out-of-hours' electricity use of the building is substantial, indicating probable poor control of the electricity consuming equipment in the building.

The maximum demand identified over this year in any one half hour was $259.4 \mathrm{~kW}$ at $15: 30$ on the 12 th December. This figure is nearly $65 \%$ of the identified installed electrical load. We also note that the total annual consumption is equivalent to having all the identified electrical power consuming equipment on for $32 \%$ of the year.

Figure 2 shows the same data but as monthly consumption in $\mathrm{kWh}$ for the same period. From this figure we can see that there is not a very large variation in electricity use between the winter and summer in the building, indicating that the electricity consumption is not very influenced by seasonal factors. This is surprising as the students are not present during the period between the start of July and the end of September.

Figure 3 shows the actual metered gas consumption for the same period. For the installed capacities noted above this is equivalent to running the boilers at full capacity for $11 \%$ of the year. The January consumption figure is misleadingly high due to meter reading dates, so if we assume a peak monthly gas consumption figure of around $220000 \mathrm{kWh}$, this provides an average gas power consumption of around $295 \mathrm{~kW}$ over the November to March peak heating period assuming 24 hour heating. The summer period is purely hot water use and equates to an average load of $1.0 \mathrm{~W} / \mathrm{m}^{2}$ or $8.6 \mathrm{kWh} / \mathrm{m}^{2}$.a

\section{Initial Findings from the Questionnaire}

The aim of the questionnaire was to assess when the occupants were present in the building, and when they used the small power and lighting under their control. The schedules of average use of the building by time of day, and day of week, are derived from the questionnaire and are shown in Figure 4.

These graphs show that the occupants reported different daily schedules for their occupancy, lights and equipment. They also reveal that the reported usage profile of small power and lighting in the building does not correspond with the actual building electricity consumption profile shown in Figure 1. This is believed to be because many rooms, such as computer terminal rooms, did not have dedicated occupants and therefore the usage profiles of the equipment in these rooms is not reported in the survey.

The occupancy profile reported is as expected, with a dip around midday for lunch, whereas the equipment schedule shows that when equipment is turned on it is not turned off at midday. The lighting schedule also reveals that on average many people turn off their lights in the middle of the day and do not turn on their lighting again until late afternoon. The questionnaire also provided an insight into the perceived monthly variation of the occupancy and hence lighting and small power use.

Figure 5 shows the average reported variation by month of occupancy over the year from the questionnaire, expressed as a percentage of the occupancy during March.

Combining the data obtained from the questionnaire profiles and data survey findings enabled us to predict consumptions using this 'bottom-up' approach. These predictions allow us to produce Figure 6, which shows the predicted monthly consumptions for electricity along with the actual monthly consumption figures from Figure 2. The total predicted annual load is around $490000 \mathrm{kWh}$, which is only about $43 \%$ of the electrical consumption actually recorded. The 'missing' $57 \%$ of the electricity consumption is thought to be from the rooms and spaces which had no single person accountable for them, such as computer terminal rooms, as well as from the common building services, including lighting in corridors, etc. This is possible as it is more likely that the equipment in these rooms will be left running continually. If we take Figure 1 and Figure 4 together we observe that $97 \%$ of the reported usage of equipment occurs between $06: 30$ and 18:00, yet only $61 \%$ of the recorded consumption occurs between these periods. 
$\%$ of maximum occupancy by time of day and day of week

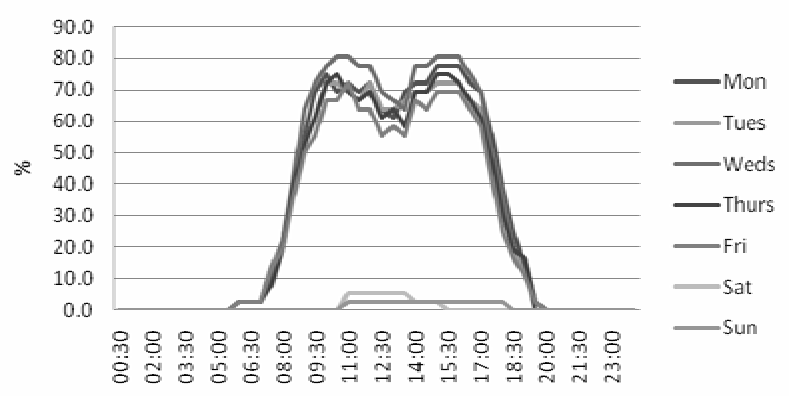

$\%$ of maximum small power load by time of day and day of week

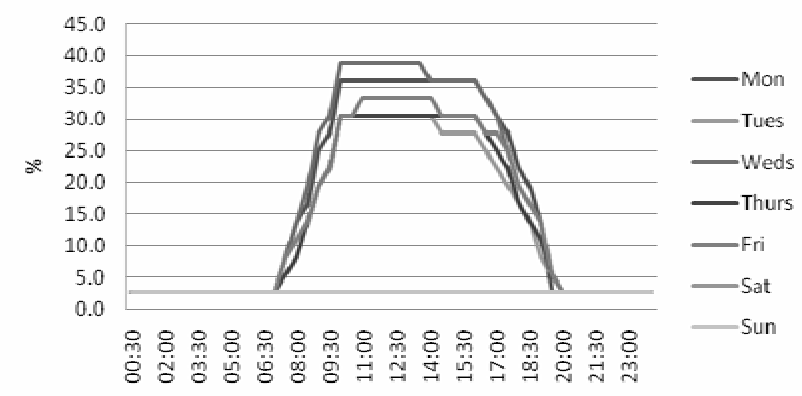

$\%$ of maximum lighting load by time of day and day of week

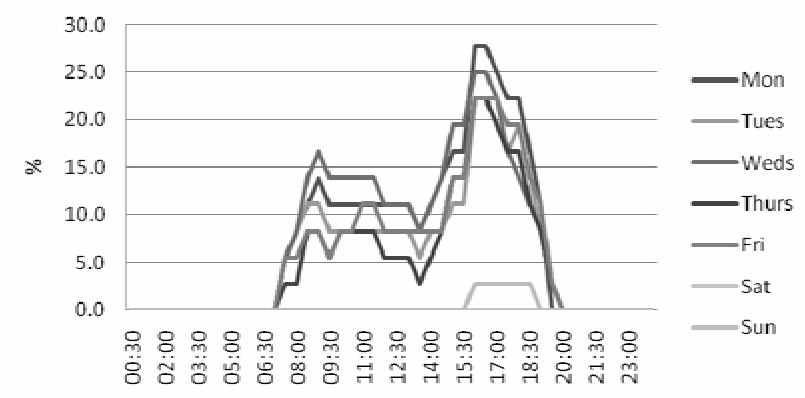

Figure 4. Daily schedules for occupancy, small power and lighting use from questionnaire.

Reported variation of occupancy by month of year

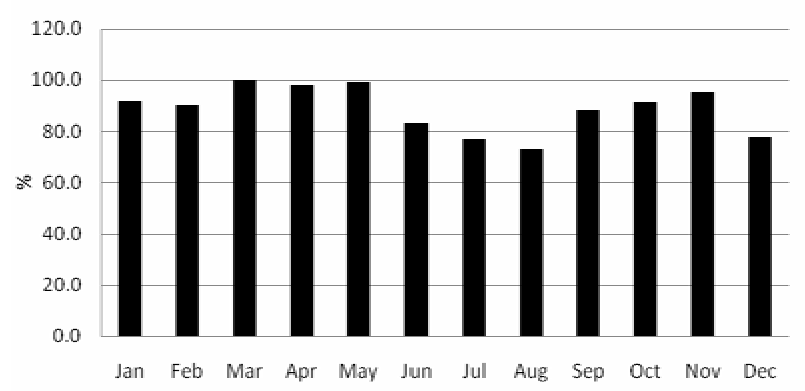

Figure 5. Monthly variation of occupancy and other internal gains expressed as a \% of March occupancy. 


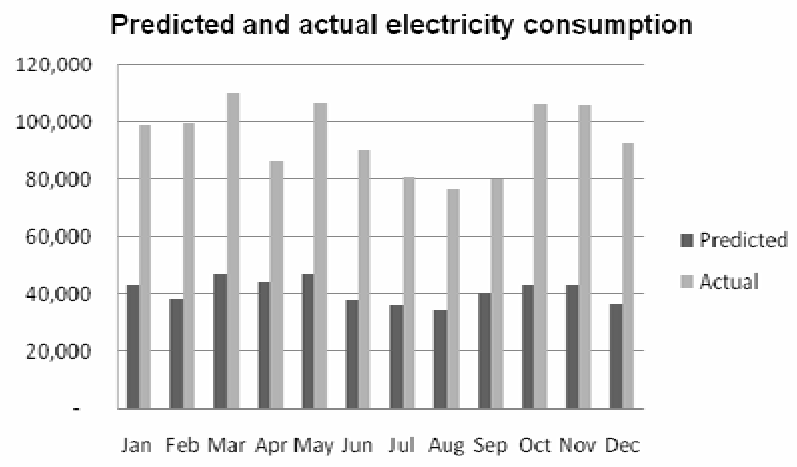

Figure 6. Predicted and actual monthly electricity consumptions.

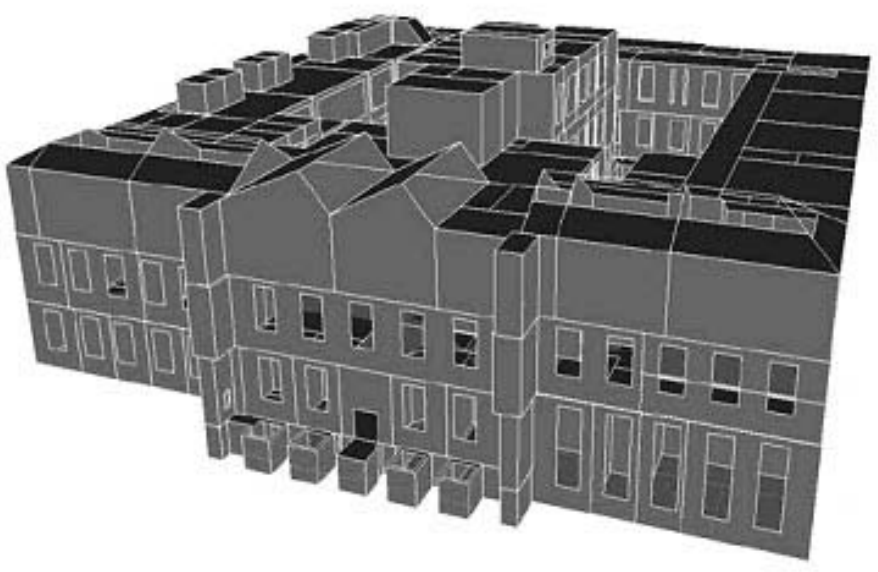

Figure 7. The Bute Building in ECOTECT.

The unreported consumption periods therefore account for nearly $40 \%$ of the total energy use in the building.

One of the key preliminary findings from the survey and questionnaire is therefore that, at the level of detail undertaken to date, they substantially underestimated the overall electricity consumption of the building.

\section{Findings from the Building Modelling}

The building was modelled in the ECOTECT tool and then the heating and cooling demands were assessed using the internal calculation engine in ECOTECT.

The ECOTECT building model was then exported for further calculation in the SBEM tool. Figure 7 shows the ECOTECT model of the building. In total there are 339 separate activity zones in this model.

The ECOTECT predicted monthly heating and cooling loads for this building, assuming $22^{\circ} \mathrm{C}$ and $24^{\circ} \mathrm{C}$ setpoints and under the weather conditions experienced between May 2006 and April 2007, are shown in Figure 8. This figure assumes no heating from June to October, and there is no allowance for domestic hot water (DHW) use. The total annual predicted heating and cooling energy demands are $1960 \mathrm{MWh}$ and $37 \mathrm{MWh}$ respectively.

Assuming an $89 \%$ seasonal energy efficiency rating (SEER) for the heating system and a $312.5 \%$ SEER for the cooling system (from the SBEM defaults), then the total predicted use for the building from this method (ECOTECT DHW, heating and cooling loads and survey/questionnaire electricity loads) 


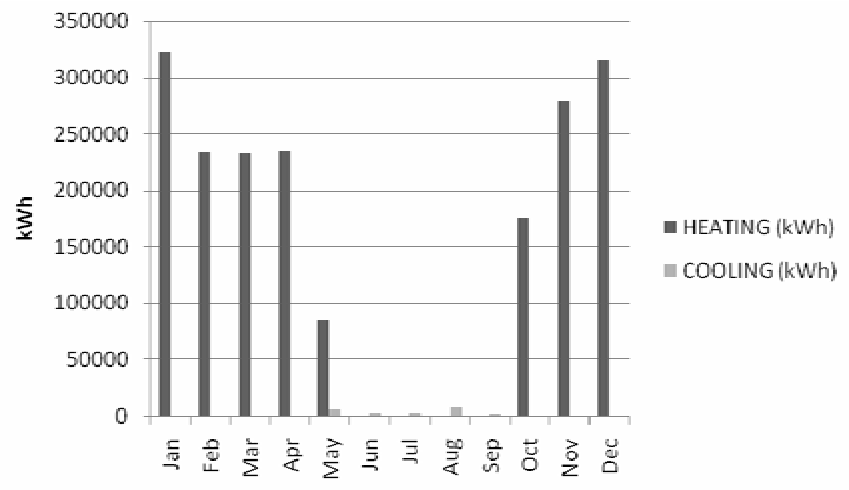

Figure 8. ECOTECT predicted heating and cooling loads.

corresponds to $45 \mathrm{kWh} / \mathrm{m}^{2}$ per annum of electricity and $177 \mathrm{kWh} / \mathrm{m}^{2}$ per annum of gas.

In comparison the SBEM model, which is based on the building layout, standard weather file for the region, fabric properties and activity type per space predicts annual electrical consumptions of $109 \mathrm{kWh} / \mathrm{m}^{2}$ and annual gas consumptions of $171 \mathrm{kWh} / \mathrm{m}^{2}$.

\section{Comparison of Models, Survey and Reality}

The findings show the ECOTECT and SBEM models provide acceptable estimates comparing the actual annual gas consumption of the building considering the assumptions made about seasonal efficiencies of the plant $\left(177\right.$ and $171 \mathrm{Wh} / \mathrm{m}^{2}$ per annum respectively compared to $191 \mathrm{kWh} / \mathrm{m}^{2}$ per annum actual). It is also noteworthy how closely they agree with each other.

The SBEM model overestimates the electrical consumption slightly, but again is sufficiently accurate to make the figures useful. ECOTECT does not predict electrical consumption figures.

Figure 9 shows the comparison between the ECOTECT and SBEM predicted monthly gas consumptions and that actually consumed (corrected for the effects of weather) as shown in Figure 3. From this figure it appears that the modelling does not accurately predict the gas consumption that well at a monthly level, although some of the differences may be due to inaccurate scheduling of the Christmas break within the model.

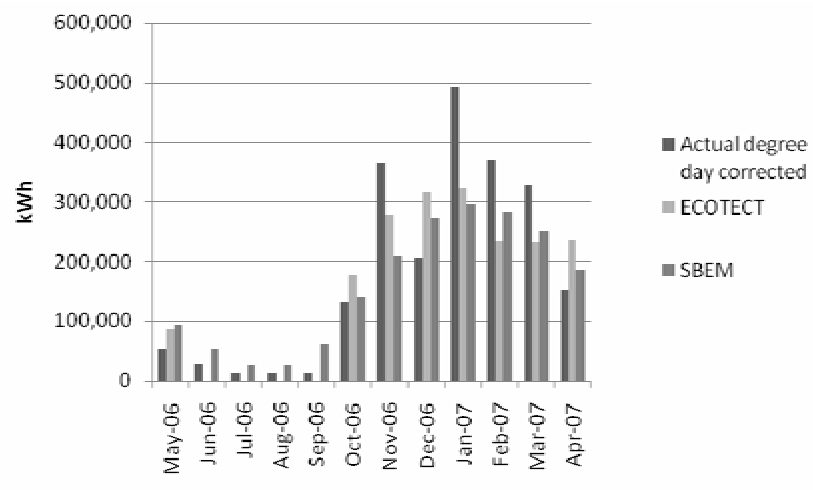

Figure 9. Comparison of ECOTECT and SBEM predictions with actual monthly gas consumption corrected for degree days. 
Neither model has yet been validated through accepted methods, but ECOTECT is known to give a reasonable estimate of the heating loads in heavyweight buildings. Therefore, even if we were to export the building to run in, for example, EnergyPlus, we would not achieve much greater confidence in the results as the main uncertainties in this type of modelling lie in the input data for the model, particularly schedules and loads.

The SBEM model is designed for compliance testing not accurate building modelling but it is, and will be, used to design and asset rate buildings and therefore its basic accuracy is important. This case study has shown that it seems sufficiently accurate in this one example for it not to be a major concern, though clearly a larger number of buildings would have to be tested to see if this finding was repeated at a statistically significant level.

To this observation we can add the encouraging fact that two very different methods of calculating energy demands matched up well with each other and reality.

A new version of SBEM is due out shortly which is specifically designed to allow asset ratings to be derived for existing buildings to produce this portion of the Display Energy Certificate (DEC) for a building, and this will be assessed in subsequent work.

The correlations found in this study between the models and reality does not necessarily mean the models are capable of always producing predictions that are close to the consumptions achieved in reality. Further buildings will need to be assessed to establish this.

For this case study, the main sources of error in the data input to both the ECOTECT and SBEM models were felt to be:

- the estimation of the internal gains or activities in each space (as shown by the difference between the predicted and measured electrical loads).

- the estimation of the schedules of occupancy and equipment use in the building (ECOTECT only, SBEM contains these in its activity descriptions).

- the estimation of the ventilation rates in the building zones.
- the estimation of the annual efficiencies of the heating and cooling equipment.

- the estimation of some of the equipment loads in use (ECOTECT only, SBEM contains these in its activity descriptions).

- the weather data used for Cardiff was a generic Cardiff file. We have the actual weather data to use in subsequent work and it is hoped this will reduce some of the error for ECOTECT. SBEM contains its own standard weather files.

\section{Conclusions}

A large industry is growing up around the ability to predict the likely Operational Energy Performance of a building in use, therefore allowing the risks of underperformance to be more accurately assessed when designing or refurbishing a building to try and reach an energy or carbon performance target as now required by several EU Member States.

The calculation methodologies as required by Articles 2, 3 and 7 of the EPBD are likely to change over time as experience is derived with the actual performance of buildings in use, and hence feasible targets become clearer.

Part of any building rating methodology is to describe the building to be assessed. The main question to be answered is how detailed should this description be in order to obtain a given level of accuracy in the prediction of energy consumption for asset rating purposes?

This case study has shown that, as might be expected, even undertaking a detailed and expensive survey of an existing building over a number of weeks can still fail to provide data of a sufficient accuracy to predict the actual consumption of a building.

This finding supports the 'activity benchmark' consumption approach adopted by the UK's SBEM methodology. These benchmarks are derived from the actual electrical consumptions of specific activities in real buildings, to allow a reasonable estimate of the actual internal gains in buildings both in use and at the design stage. For this building the benchmarks used in SBEM would appear to be quite accurate, but we would need to assess more buildings before greater confidence could be obtained that this was repeatable. 
The strong possibility exists that in future we will require more accurate data, or more focussed activity descriptors, or, perhaps most useful, a move from a single number descriptor of consumption to a range which could work through the calculation to give a range of potential performance at the end of the calculation.

The main conclusions from this work are:

- The survey and questionnaire as conducted were not able to predict the magnitude or profile of the electricity consumption of the building.

- The modelling, survey and questionnaire seemed able to reasonably accurately predict the heating and cooling demands of the building using ECOTECT. The SBEM prediction was also reasonably accurate.

- The SBEM estimate of the electrical consumption got far closer to the measured consumption than the detailed survey.

Future work will revisit the building with more detailed surveys of those areas not under the control of any one person, to see how much of the installed equipment is left on. The work will also more accurately define the energy consumption ranges of the equipment in the building, as well as submonitoring those areas where major electrical energy consumption is considered to be occurring.
The results of this further work will hopefully result in published profiles for individual energy consuming equipment to assist in the 'bottom up' approach to modelling. However, it appears that the 'top-down' approach embodied in methods such as benchmarking are likely to prove more robust under normal circumstances.

As the future studies provide more data for the modelling we aim to produce papers showing in practice what needs to be known to provide a given level of confidence in the modelling results as this information is crucially missing at present.

\section{References}

EPBD: (2002). "EU Directive 2002/91/EC Energy Performance of Buildings Directive (includes PGN37 Standards supporting the Energy Performance of Buildings Directive)", European Union.

ECOTECT: www.squ1.com - accessed $20^{\text {th }}$ July 2007

SBEM: www.ncm.bre.co.uk - accessed $20^{\text {th }}$ July 2007 